\title{
TLC at APSA Track Summaries
}

\section{INTRODUCTION}

\section{Amber Dickinson, Washburn University Jyl Josephson, Rutgers University, Newark}

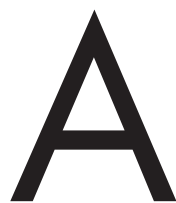
$s$ is true of most events in 2020, the third TLC at APSA one day "conference within a conference," held on September 12, did not take place in the manner originally planned. However, in virtual format, TLC built successfully on the spirit and format of the previous TLC at APSA and TLC stand-alone meetings. Indeed, the 2020 conference marked a very propitious moment to consider our pedagogy and to share and discuss our work as teachers and learners in the discipline of political science. The theme of the conference was "Teaching Democratic Principles through Political Science Education," and attracted more than 175 participants and scholars from fields across the discipline.

The day began with a keynote by Edie Goldenberg (University of Michigan, Ann Arbor), titled "Back to Basics in this New Era." Professor Goldenberg was introduced by APSA President Paula D. McClain and APSA Executive Director Steven Rathgeb Smith. After the keynote, the TLC at APSA Networking Reception took place. Given the virtual format of the meeting, the reception was broken up into moderated breakout rooms that focused on teaching-specific themes. These breakout sessions were an opportunity to promote debate and discussion amongst conference participants. Each session had a formal theme and a moderator, however the conversation was organic and allowed for interesting and thought-provoking discussions. The themes were as follows:

- Integrating Race, Gender, and Politics into Online-Only Courses

- Successful Transitions from Face to Face to Online Teaching

- Share and Solve: Experiential and Service Learning during the COVID-19 Pandemic

- Encouraging Meaningful Civic Debate in Classrooms

- Integrating Discussions about 2020 Current Events into American Government Courses

Conversations in each of these sessions prepared participants for a day of discussion and idea-sharing. One of the wonderful features of TLC is that participants are asked to follow their "track" for the day, and this means that conversations can be continued from one session to the next. This format held true even as we met virtually, as you will see in the track summaries below.

TLC has a tradition of offering teaching workshops, and the third TLC at APSA featured the following workshops, offered simultaneously: "Getting Prepared to Teach Civic Engagement in 2020 and Beyond," led by Elizabeth Matto (Rutgers University, New Brunswick), Elizabeth Bennion (Indiana University South Bend), Alison Rios Millett McCartney (Towson University), and
Dick Simpson (University of Illinois, Chicago); "Playing Games to Teach Comparative Politics," led by Victor Asal (University at Albany, SUNY) and Joseph Roberts (Roger Williams University); and "Using ICONS Simulations to Apply IR Theory to Real World Problems and Issues," led by Joyce Kaufman (Whittier College) and Jeanette BenFarhat (Santa Rosa Junior College).

\section{SIMULATIONS \& GAMES}

\section{Josh Franco, Cuyamaca College}

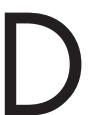
uring our track, four papers were presented that offered a range of perspectives about how simulations and games can be used in the classroom to help improve learning, strengthen community, and engage students in online learning format.

Gretchen Gee (Northern Arizona University) presented "Classroom Simulations and Student Engagement: Evidence from a Two-Wave Survey." Along with her coauthor Kelly Siegel-Stechler (Johns Hopkins University), they asked the question: do simulations really make a difference? To help answer this question, they examined whether participation in classroom and Model United Nations simulations leads to increases in civic attitudes and behaviors by comparing student survey responses before and after taking part in a simulation. Gee and Siegel-Stechler found that student surveys indicated that participating in a simulation was significantly associated with increases in both the number of civic activities in which students participated and with the amount of time students dedicated to these activities, even after controlling for pre-simulation levels of civic engagement as well as demographic indicators and fixed effects by group.

Marc Hooghe (University Leuven) discussed his paper: "Using Mock Elections in the Class-Room: A 2003-2019 study in Belgium." Sharing 16 years' worth of data, Hooghe was able to demonstrate how annual mock elections at his university's campus helped engage students, improve their understanding of the different policy issues, and offer a clearer sense of where the varying political parties stood on the issues. In Belgium, given that elections are held every five years and seeds are awarded on a proportional representation basis, without mock elections in non-election years, there can be cohorts of students who don't engage in the electoral dialogues during their time at university. But, what Hooghe's work demonstrates is that it's very useful to maintain a mock election every year so as to help students develop the habit of paying attention to national policy issues and practice weighing in on them in a learning environment.

Mark Hamilton (Inter-American Defense College) presented "Power of Metaphor: Linking Ideas to Experience via Story, Symbol and Simulation." Professor Hamilton teaches at an institution whose mission is "to prepare military officers, national police and civilian government officials from member states of the OAS to assume senior strategic-level positions within their gov- 
ernments, through graduate and advanced-level academic programs in defense, security, and related disciplines focused on the hemisphere." Teaching in this setting requires finding ways to communicate across different languages and cultures to ensure an understanding of the material, as well as an exchange of information between students. To achieve this, Hamilton uses the power of metaphor and walks students through a range of processes by which to understand information and to convert it into knowledge. Additionally, creating a space where professionals can open up about their personal experiences related to their role in their nation's military or law enforcement branches, can improve the learning environment.

Simone Bohn (York University) discussed her paper: "Synchronous Blended Teaching: Creating a Community of Engaged Learners." Before the pandemic, Professor Bohn was already teaching students in the online space. The question she had for herself was how can I better engage my students using video conferencing software to help promote a sense of community in an online course? Her findings suggest that having meaningful discussion prompts, smaller groups interacting, and consistent outreach from her as a professor, helps to promote a welcoming and supportive online teaching environment.

Throughout the four paper presentations, panelists and participants asked a range of questions. Two key questions were: (1) how can the work that was done in a face-to-face setting be converted into the online space? and (2) how can we develop hybrid modalities given the strengths of video conferencing?

\section{CIVIC ENGAGEMENT EDUCATION}

\section{Robert W. Glover, University of Maine}

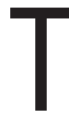
his year's sessions on civic engagement education grappled with the challenges of designing and executing engaged courses in the context of logistical barriers posed by the COVID- 19 pandemic, but also a polarized political environment in a tense election year. Moving beyond the challenges of the immediate context, track participants engaged with questions related to the immediate and long-term impacts of civic education, how we attempt to measure them, what impacts we can reasonably expect civic education to produce, and the importance of intentional program design.

Keynote speaker Edie Goldenberg (University of Michigan) set the tone by discussing the critically important role we can play at our universities to increase student voter registration and turnout. In addition, she highlighted our vital responsibility to ensure that students are making educated choices at the polls. This work is made more challenging in the context of a pandemic, but is no less essential. Similarly, the challenges of fostering civic engagement in 2020 and beyond were the subject of a workshop by Elizabeth C. Matto (Rutgers University), Allison Rios Millett McCartney (Towson University), and Dick Simpson (University of Illinois, Chicago).

Structuring engagement in the context of an increasingly fractious and polarized political environment was a consistent theme in the track sessions and within informal networking and breakout sessions. Christi Leigh Siver (College of Saint Benedict) highlighted this theme in her presentation on the use of debate in political science coursework. Siver argued that, problematically, popular understandings of debate essentialize it into

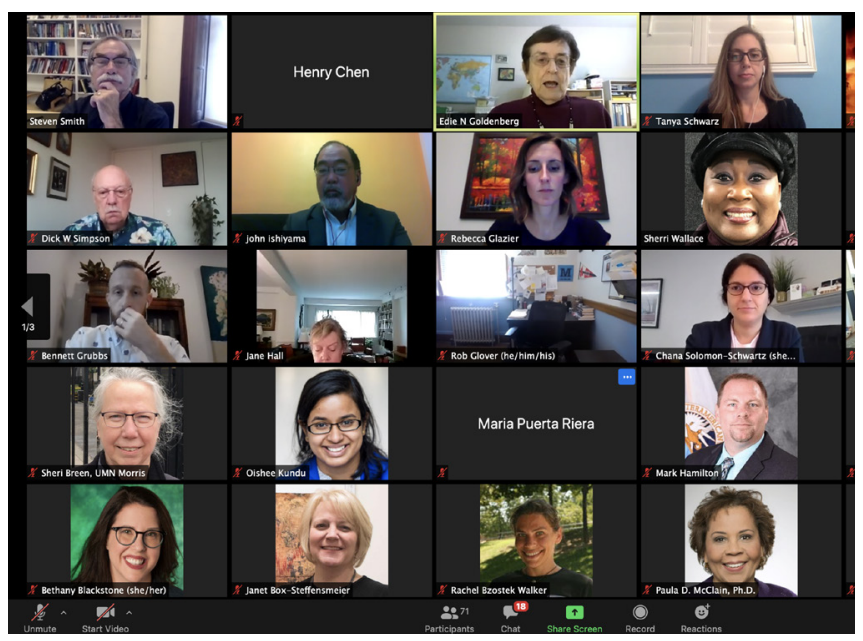

Above: TLC at APSA participants listen to Edie N. Goldberg deliver the keynote address

models that create settings totally unconducive to listening, critical thinking, argument construction, and civil discourse. While debate has numerous benefits that align with what we aim to do in our discipline and in our courses, these are not realized if we simply replicate problematic existing models of debate. Siver offered helpful clarification on how students are actually enriched through debate and best practices for structuring debate in ways that unlock its pedagogical benefits.

Effective civic engagement education also means being able to measure the impact of the interventions we are having on students, a robust and growing area in the scholarship in this area and a theme highlighted in track sessions. Laura Roost (Newberry College) and Patrick McKinlay (Morningside College) presented their work which explored the long-term impacts of civic engagement coursework conducted over 16 years ago. This qualitative assessment is part of a larger project to explore long-term impacts of civic engagement education, a difficult but critically important area which has traditionally been underexplored (in part because of the challenges of doing such work).

Along similar lines, Michael T. Rogers (Arkansas Tech University) and Donald M. Gooch (Stephen F. Austin University) sought to better understand when and under what conditions civic education impacts civic literacy and civic engagement. They find that civic education has the greatest impact on civic literacy when overall political knowledge is low; there are declining returns to civic literacy as students are provided more civic education. On a related note, they identify what they call the "civic engagement conundrum" where a one-semester American government course has no significant impact on civic engagement and may even negatively impact political interest and engagement. Such insights are instrumental in thinking about civic engagement programmatically and systematically, and where our interventions can have the greatest impact.

Judithanne Scourfield McLaughlin's (University of South Florida, St. Petersburg) presentation on the FL Civic Fellows Program provided an example of such high impact practices, and an inspirational model for civic education as well as robust university-community partnerships. The program is an innovative and intensive partnership between the university and the YMCA Youth In Government program that provides hands-on civic education to middle and high school students, with a focus on the state legislative process and policymaking. 
While 2020's public health situation and overtly hostile political environment forces us to be more intentional in how we design civic engagement experiences, this year's track participants offered clear signs that our pedagogical efforts will persist. Furthermore, they will continue to yield powerful outcomes for our students. Track participants throughout the sessions offered insights on what they had done in the past, and the ways that they had updated or adapted these interventions to account for the demanding current circumstances. Throughout, participants were reminded that, despite an unconventional and disruptive year, civic engagement remains an adaptive and impactful tool for political science educators.

\section{TECHNOLOGY \& INNOVATIVE PEDAGOGY IN THE CLASSROOM}

\section{Marcus D. Allen, Stella and Charles Guttman Community College, CUNY Sarah Wilson Sokhey, University of Colorado, Boulder}

\section{T} he 2020 APSA TLC and Innovative Pedagogy in the Classroom Track papers were organized around two themes, Bridging Technology and Critical Engagement and Community Engagement and Experiential Science. Ironically, the global pandemic forced the world to lean on technology to maintain some semblance of normality or continuity. The rapid shift to remote work, social distancing, and distance learning in mid-semester last spring continued into the Fall 2020 semester. Universities have relied on various modalities from Learning Management Systems (LMS), to web conferencing platforms, all of which have left an indelible mark on education.

The Technology and Innovative Pedagogy in the Classroom papers' themes centered on civic and critical engagement, each of the track participants examined civic and critical engagement. The civic engagement participants' papers focused on bridging the gap between theory and the real world in innovative ways, especially considering the current pandemic. The critical engagement papers approached technology and innovation via social media and scenarios. The papers demonstrated a range of innovative pedagogy with varying degrees of using technology as a central role.

The first paper, written by William O'Brochta (Washington University in St. Louis) asks, "How can students develop a deeper understanding of course concepts that make current content relevant to their lives?" The paper discusses small scale community engagement through a comparative perspective by scaffolding engagement through three assignments, a "community identity profile," a "field observation," each requires about an hour, and a "community organization research" project that needs three class periods, where "students developed an environmental racism training," thus "bringing theory to practice." The paper draws two important conclusions, one is even the smallest civic engagement activity has significant impact; and the other is reflection is critical for students to journal their experiences, and many found that "politics is relevant in their lives." Even more notable, it is possible to participate in community engagement online through a comparative perspective.

The second paper, by Jeffrey Nonnemacher (University of Pittsburgh) and Sarah Wilson Sokhey (University of Colorado Boulder) discussed the establishment of an undergraduate research laboratory at the University of Colorado Boulder-the STUDIO Lab-in which students collaborate with faculty and PhD students as research assistants while also receiving additional opportunities for research training and professionalization. The lab emphasizes practical research experience in which students can get hands-on training as part of a "learning by doing" initiative in the Department of Political Science. As part of their participation, students are encouraged to present their research at the university and professional conferences and to publish in the department's undergraduate journal, the Colorado Political Science Review. During the pandemic, STUDIO successfully transitioned to be fully remote, enabling students to maintain a meaningful connection with faculty and PhD students during a challenging time.

The third paper, by Brittney Perry (Texas A\&M University) asks, "Can service-learning reduce inter-group prejudice and anti-immigrant attitudes?" Using Allport's Contact Theory, the paper seeks to examine two different service-learning assignments and student attitudes. The first assignment integrated community service and academic curriculum. Half of the students worked with a local immigrant group and participated in a citizenship class, connecting the real-world civic skills applications to reduce prejudice. The second assignment included a planned field trip to the Brazos Valley African American Museum that did not meet Allport's conditions and was canceled due to COVID-19. The revised assignment featured select readings from African American Bryan, Texas: Celebrating the Past with Written Reflections by Oswell Person. An important overall conclusion is that the service-learning project met Allport's four conditions.

The last two papers addressed critical thinking and critical engagement questions. The first submission, by Anne Marie Baylouny (Naval Postgraduate School) "Pinterest for Politics: Curated Collections and Social Media Assignments to Spur Critical Thinking," asks "how to integrate critical thinking with teaching?" And, "how to spur critical thinking outside the classroom?" The class was organized around a larger question of "what creates political change in the Middle East?" This theory with application assignment was designed to help students take a critical thinking approach to hopefully understanding that daily media consumption is "constructed," as a way to articulate a point of view from the author. The curated collection was a form of "Digital Storytelling." As part of the political change assignment, students searched through digital media sources to locate artifacts best able to demonstrate their viewpoint. Students universally reported enjoyment with the group, but particularly interesting is the finding that minoritized groups and women were "particularly creative and comfortable." Many of the illustrations included cartoons used as "strong political devices." The second assignment featured a "social media campaign against misconceptions of refugees as case studies" and required students to work in groups in class to think about "common mis- 
conceptions" and why they are wrong and created "a social media campaign to refute misconceptions and promote an alternative, correct, idea of refugees." Some key lessons from this assignment include: a positive response to the curated political change collection and tweaking the refugee collection to focus on a smaller dimension of refugees.

The second paper, by Andrea Malji (Hawaii Pacific University) discussed civil resistance and non-violent movement, covering content such as protests, strikes, and civil disobedience through a historical lens, and highlighting civil resistance as a challenge to colonialism through art from a global perspective. Students were assigned various identities and given three scenarios, ranging from "an Indigenous group in the Amazon engaged in civil disobedience with a logging company that has state support," to "an authoritarian state suppressing information from the people," and "a student death during a peaceful protest against government's involvement with a war, and the officer claimed that the student was reaching for a gun." With their identities and sce-

"In a resource-intensive world where faculty and students face increasing demands, technology can be a useful tool to enhance civic engagement meaningfully, even with time constraints." narios, students were asked to respond to 198 examples of civil resistance. Students selected a movement they would follow for the semester and posted weekly responses on the discussion board before discussing the reactions. There was overwhelming evidence that the class helped them understand the key four educational outcomes, ranging from a low of $76.5 \%$ on one measure and as high as $88.3 \%$.

The smallest amount of community/civic engagement activities impacts internal efficacy. In a resource-intensive world where faculty and students face increasing demands, technology can be a useful tool to enhance civic engagement meaningfully, even within time constraints.

\section{DIVERSITY, EQUITY \& INCLUSION IN THE CLASSROOM}

\section{Megan Becker, University of Southern California}

T he TLC at APSA provides a yearly forum for political science faculty to share the challenges we face as educators and the strategies that we use to meet them, but this year felt different. Many of our students are struggling; many of us are, as well. While recent events-the COVID-19 pandemic, widespread protests against police brutality and racial injustice, a contentious presidential campaign season-have affected all of us, the crisis has placed a disproportionate burden on those in marginalized communities. In this context, having meaningful conversations about promoting diversity and inclusion in our classrooms is critical, even existential.

Our sessions began with a conversation regarding the challenges that we were facing in our work as educators. Faculty shared their concerns about doing their work as teacherscholars (and meeting the expanded needs of their students) while also attending to the needs of their families. A recurring theme was the need for support systems and resources for faculty and students alike and the need for advocacy within our institutions and the discipline. Many institutions have recently added or expanded diversity, equity, and inclusion initiatives on campus, and those of us gathered noted that these changes should be understood as first steps and that DEl programs need to be supported and funded to have impact.

While many of the challenges we face may be best addressed at these higher levels, the place where we have most control as faculty is within our (now virtual) classrooms. Our presenters brought ideas and suggestions for how we could make our courses more inclusive and accessible. One theme was increasing the diversity of voices in our assigned readings. Ruth Ediger (Seattle Pacific University) spoke of her experience adding culturally responsive content to a course on International Law; Andrew Szarejko (Georgetown University) discussed how to incorporate Indigenous experiences in course topics across subfields; and Chana Solomon-Schwartz (University of Tennessee, Knoxville) provided a stock-taking of diversity of authors on syllabi across the country.

Another major theme was the imperative to understand our students' specific needs and strategies we can use to meet them where they are. Michael Adams, Antoinette Christophe, and Luis Perez-Feliciano (Texas Southern University) spoke of their efforts to make their American Politics courses relevant for their Latinx student population. Lauren Harding (Tennessee Tech University) presented a syllabus design approach that gave students greater autonomy in choosing how they would be assessed. Other attendees shared helpful resources, including readings, syllabus language, and online lesson plans (including those from the APSA Educate website).

There is no one-size-fits-all prescription for creating an inclusive classroom. Our approaches must be tailored to our contexts. What might work best at an $\mathrm{HBCU}$ might not be as effective at a Hispanic-Serving or Primarily White Institution. What works best at a four-year residential college might not be as effective at a two-year institution where students commute to campus. And this is where events like the TLC at APSA generate value for participants-a forum to acknowledge our common challenges, share our strategies, and brainstorm the adaptations and approaches that we can take within our own context. We do better and we are better when we learn from one another.

\section{CONCLUSION}

The opportunity to come together with our peers to discuss teaching is invaluable. During this uncertain time, it is imperative that we continue to engage one another to brainstorm ways to improve our teaching methods and stay motivated. Additionally, our community shares the common goal of remaining dedicated to teaching our students, and TLC is an opportunity to help keep us inspired as we pursue that objective.

We would like to express our appreciation to the TLC program committee, who made the work of organizing TLC at APSA much easier: Marcus Allen, Megan Becker, Bethany Blackstone, Josh Franco, and Robert Glover. 